\title{
ASTROLOGÍA Y MEDICINA: PAUTAS DE INVESTIGACIÓN EN LAS FUENTES MEDIEVALES ESPAÑOLAS
}

\author{
SUMARIO \\ I. Introducción. - II. El aspecto historiográfico hasta el momento pre- \\ sente. - III. Teoría. - IV. La praxis. - V. La conexión médico-astrológi- \\ ca. - VI. Hoy el historiador. Provecho material. - VII. Médicos y astrólo- \\ gos peninsulares. - VIII. Manuscritos y códices.
}

\section{INTRODUCCIÓN}

Quizá sea necesario realizar un pequeño exordio que explique el motivo por el que estas dos disciplinas, en apariencia con poco en común, van ligadas de esta manera. La evolución de la medicina desde "ars» medieval hasta ciencia positiva es muy diferente de la astrología que parte como compañera y colega en la Universidad medieval y que es hoy doctrina de poco prestigio entre los hombres de ciencia. Sin embargo, creemos que, en efecto, se puede hablar de medicina astrológica con plena propiedad al referirnos a la medicina medieval de forma general. Para comprender esto de mejor modo es necesario tener en cuenta que el mundo medieval es un mundo integrado, es decir, que en él todos sus elementos conceptuales se interrelacionan profundamente. La aproximación a la naturaleza, considerada como el agente reparador por excelencia, es defendida por médicos musulmanes, judíos y cristianos.

La razón astrológica. La astrología medieval es heredera de la gran tradición clásica, simbolizada en la figura de Claudio Ptolomeo que en su "Tetrabiblos» marca un rumbo que sus continuadores modificarán en detalles accesorios pero sin alterar nada de forma significativa. También el romano Marco Manilio en su "Astronomicon» nos aportará un modelo de primer orden, superior a Ptolomeo por lo que se refiere a su más fácil manejo, literario y de volumen. Sin embargo, el auge astrológico se producirá como consecuencia del paso de conocimientos helenísticos a Europa Occidental merced a la influencia del crisol cultural islámico. Es un proceso lento, notorio ya de forma 
decidida desde el siglo XI, que se consolida en el XII y adquiere un auge tremendo en el XIII, apareciendo grandes obras de traducciones hebreas y/o musulmanas. A lo largo de los siglos XIV y XV, por fin, proliferan los tratados, las traducciones son múltiples, el utillaje astronómico mejora de forma considerable y la astrología desciende hasta el último peldaño del estamento popular. A consecuencia de esto, la astrología judiciaria se desarrolla de forma considerable. Evidentemente, es notorio que el aspecto fundamental que debemos cambiar es la visión simple del astrónomo medieval como la de un hombre con prejuicios astrológicos. Por el contrario, son estos astrólogos los que desarrollan temas y campos de estudio astronómicos en los momentos que no ocupan en el campo judiciario, su labor esencial.

Así, llegados a este punto, parece que la astrología tiene una innegable trascendencia en el mundo medieval a través de dos vectores estructurantes, aunque no los únicos, de esta sociedad que son: 1. el científico, 2. el político.

Como ejemplo del primero notemos que es una especialidad de enseñanza regulada en múltiples Universidades medievales europeas. En nuestra península destaquemos el egregio y bien conocido caso de Salamanca '. En cuanto al segundo vector, bástenos recordar la importancia de la publicación de predicciones de astrólogos como arma propagandística en la contienda que enfrentaba al Rey de Francia y al Duque de Borgoña y su efecto en la opinión pública ${ }^{2}$.

La razón médica. Debemos tener en cuenta, en este caso, la importancia de una tradición clásica que, en sus supuestos teóricos, tendrá una larga vigencia. Hipócrates y Galeno son dos personajes que llenan cualquier tratado sobre el tema por las múltiples referencias y alusiones que a ellos se hacen incluso, a veces, por la copia simple y llana. En época visigoda persiste una tradición celosamente mantenida y conservamos referencias al ejercicio médico tanto de San Isidoro como en el Liber Iudiciorum entre las fuentes fundamentales '.

En Hispania, tras la conquista musulmana son mozárabes los mejores médicos, como señala con acierto Luis Granjel. Ibn Ruman, citado por Ibn Juljul como profesional del mayor prestigio que llegaría a hacerse rico, es un buen ejemplo de ello. En el siglo X, el más importante médico de la Península

' Vid. F. Cantera Burgos, El juicio salmantino Abraham Zacut, Madrid, 1931.

2 M. PRÉAUD, Les astrologues à la fin du Moyen Age, París, 1984, pp. 133-156.

"Vid. Etimologias, Libro IV, "De medicina» y en el libro VI del Liber Iudiciorum. Asimismo L. Graniel en su $H^{a}$ General de la Mèdicina Española, Salamanca, 1981, I, pp. 48-53. 
es cristiano, Abd Allah Yahya ibn Ishaq, convertido posteriormente al islamismo".

A partir del siglo $\mathrm{X}$, con el esplendor andalusí, los médicos hispanomusulmanes viajan y contactan con médicos orientales, receptores del conocimiento griego. Asimismo reciben textos de Oriente.

Desde el siglo XIII, la decadencia política, la pérdida de ciudades y la convivencia de musulmanes con cristianos bajo soberanía cristiana imponen unas nuevas coordenadas para el desarrollo de la medicina peninsular.

Así ya en el XIV y XV se puede hablar de medicina profética en el Islam peninsular y del desarrollo de prácticas astrológicas y psicomágicas, aunque éste no sea nuestro objetivo, entre los profesionales cristianos, o moriscos, que los tratan a éstos'.

\section{EL ASPECTO HISTORIOGRÁFICO HASTA EL MOMENTO PRESENTE}

Internacionalmente, el menosprecio por la astrología, cuya práctica generalizada desaparece en el XIX, ha impedido hasta hace poco la conformación de estudios sobre ésta, que de forma seria y rigurosa tratasen de examinar los aspectos de una ciencia medieval de tan grande importancia.

Afortunadamente, hoy no es necesario ser cardenal para poder ser un magnífico estudioso de la Historia de la Iglesia. Así, los escépticos tenemos un camino en la ciencia histórica pese a que nuestros temas de estudio tengan poco de tangible mensurable.

Desde el punto de vista de la historiografía científica es necesario mencionar a Thorndike, Kibre, Sarton, etc. Por otro lado los modernos astrólogos cientificantes presentan figuras tan curiosas como las de un Choisnard o un Kraft, que pueden aclararnos muchos conceptos oscuros de la astrología medieval ${ }^{\circ}$.

Muy fructífero es el camino emprendido en la École de Chartes, significándose la obra de Emmanuel Poulle y, sobre todo, la de Maxime Préaud. Asimismo, E. Poulle ha prometido un fascículo monográfico sobre astrología medieval en la colección «Typologie des sources du Moyen Age Occidental» ?

'Luis GRANJEL, op. cit., p. 56.

' Entiéndase medicina del Profeta. Incide más en el apartado psicológico de la enfermedad. Deriva hacia el curanderismo. Vid. L. GaRCía BALLESTER, $H^{4}$ social de la Medicina en la España de los siglos XIII al XVI, Madrid, Akal, 1976, pp. 118-120.

- Vid. Bibliografía.

' E. Poulle, en el fascículo núm. 39 dedicado a "Les sources astronomiques», Turnhout-Belgium, 1981, p.7 
Finalmente, las publicaciones periódicas de revistas astrológicas ponen a nuestro alcance el bagaje de un astrólogo de la manera más actualizada posible, permitiéndonos entrar en las habitaciones de éstos a fines del siglo $\mathrm{XX}^{8}$.

En el panorama internacional, la medicina, por el contrario ha registrado una serie ininterrumpida de estudiosos que enlazan el siglo XVIII con nuestros días. Los grandes trabajos, en un estudio general sobe la ciencia, como el de Sartón y otros, y la configuración de publicaciones periódicas de revistas de Historia de la Medicina han conseguido producir un aceptable grado de producción bibliográfica respecto a la astrología. ${ }^{9}$ Sin embargo, a pesar de todo, de forma global es alto el número de códices y manuscritos medievales que todavía esperan su turno, cubiertos de polvo en nuestros archivos.

Aún más, parece como si la profesión médica tuviese especial cuidado en revisar textos que hoy están alejados de la ortodoxia de su profesión. Sin embargo, como historiador no puedo por menos que anotar la necesidad de no abandonar a su suerte a textos medievales que nos permiten conocer el estado real de aplicación de la medicina en estos siglos. Llámese medicina astrológica, o incluso mágica, aunque esta última denominación es apartada y plenamente rechazada por multitud de astrólogos-médicos medievales ${ }^{10}$.

En cuanto a lo que afecta a la astrología en nuestro país, la producción de obras astrológicas es ininterrumpida desde Cayo Julio Hygino que escribió el "Poeticon Astronomicon», en el siglo I, hasta el "Tratado sobre las causas de los Cometas» de P. Cassany, en 1737.

Ya en el siglo XIX se hacen descripciones de textos antiguos, elucubraciones sobre procedimientos astrológicos como Pérez de Acuña, o preocupados por desacreditarla con criterios positivistas como Sarmiento de Cobos ".

En nuestro siglo los estudios astronómico-astrológicos tienen figuras des-

8. Destaquemos las siguientes: Astrologie (Paris, 1934), Les Cabiers Astrologiques (Niza, 1938 y ss.), "L'Astrologue», revista de CAL (Paris, 1968 y ss.), Sous le ciel (París, 1936 y ss.), Le voile d'Isis (París, 189 a 1935)

9 A partir de publicaciones como por ejemplo: National Library of Medicine, Bibliography of the History of Medicine. Nordisk, Medicinhistorisk Arsbok, Stockolm, 1974-1987. Studies in History of Medicine and Science, New Delhi, 1977-85. History of Science, 1962-1986, etc. Añadamos a esto las innumerables publicaciones de actas de Congresos sobre el tema, significándose especialmente las de los Congresos Internacionales de $\mathrm{H}^{*}$ de la Medicina. En España, los Archivos Iberoamericanos de $\mathrm{H}^{2}$ de la medicina (1949), hoy transformados en Asclepio, tienen una importancia que quizá no corre pareja con su difusión, siendo su conocimiento mucho más limitado entre los profesionales de la historia.

10 Es algo que aparece muy claro en Las Partidas, Ley 17, Título 9, Partida VII y en las Ley 1, Título 23, Partida VII. En la práctica no lo es tanto, vid. M: Préaud, Les astrologues..., cap. 9. "Astrologie et magie».

1 Vid. PÉREZ DE ACUÑA, La astrología judiciaria, o S. de COBOS, Errores y preocupaciones astrológicas (1878). 
tacadas en Millás Vallicrosa, en su continuador Vernet, y en autores de publicaciones importantes, aunque poco numerosas en este terreno, como $\mathrm{P}$. Cantera Burgos o M. V. Amasuno ${ }^{12}$.

En cuanto a la producción bibliográfica sobre medicina en España podemos considerarla como de un alto nivel. Es patente una larga tradición que Granjel resume en varias etapas: 1. San Isidoro 2. Ibn Juljul 3. El Renacimiento 4. Los Médicos-militares, de 1750 a 1850 5. El siglo XIX y primeras décadas del XX. 6. La Postguerra".

La figura de Laín Entralgo, contradictoria, ocupa un lugar destacado en los últimos años tanto por la escuela de Historia de la medicina de Salamanca, Madrid, Valencia... como por la elaboración de una Historia Universal de la Medicina, de 1971 a $1975^{14}$.

\section{TEORÍA}

Bases teóricas de la astrología. Hoy no presenta problema alguno el aceptar que los conceptos estructurantes de la astronomía-astrología se remontan al período caldeo. Las tablillas sumerias nos muestran complicados cálculos lunares, solares y planetarios, incluso más allá de lo que se pensaba hace poco tiempo. Las 12 casas astrológicas estaban ya constituídas ${ }^{1 s}$.

Parece también ser moneda común que los egipcios pasen por deudores de los caldeos, de manera parcial, por lo que a temas astrológicos se refiere.

Griegos y romanos sistematizan de forma lógica todo este corpus de conocimiento, que la tradición atribuye llegado a Europa de la mano de Beroso. Claudio Ptolomeo en su «Tetrabiblos» compone una obra en la que el sistema geocéntrico es la base de la organización del horizonte astronómico. Es obra de obligada consulta para toda la Edad Media. Desde el punto de vista humano su sistema es plenamente válido, ya que organiza su cielo y cubre con sus explicaciones los interrogantes de la sucesión día-noche, verano-invierno, etc.

Los diferentes Almanaques y Tablas Astronómicas permiten conocer las efemérides estelares, ayudan a la navegación, etc. ${ }^{16}$.

Marco Manilio en su «Astronomicon» reduce la obra de Ptolomeo y no

12 Vid. Bibliografía anexa.

13 L. GRANIEL, op. cit., pp. 13-26.

14 Ibidem.

is A. BOUCHÉ-LECLERCQ, Astrologie grecque..., p. 139, piensa que no hay correlación entre Virgo y diosa o signo caldeo alguno. Hoy se atribuye inequívocamente a Nidaba.

16 Las tablas de Al-Jwarizmi, las alfonsíes, etc. 
aporta innovaciones de interés. Resulta más práctico en su manejo y de ahí su empleo abundante.

Resaltemos que el principio básico que se aplica a toda la teoría o dogma astrológico es el de la analogía. No es casualidad. El principio fundamental que sustenta es la idea de que el macrocosmos es semejante al microcosmos, idea que tiene amplia tradición ya en medios helenísticos ${ }^{17}$.

Las mareas, el ciclo de ovulación femenina, los cambios en la savia de las plantas, etc. y su relación con la Luna eran prueba manifiesta de ello. Asimismo, el ciclo solar de siete años, ciclo de renovación celular, es un ciclo que ordena las etapas de la vida humana. En resumen, es la visión del hombre como «Dei imago» la que se propone. Lo inferior se construye a semejanza de-lo superior ${ }^{18}$.

Un problema surge para todos los astrólogos. ¿Cómo compaginar su labor con la existencia de la Iglesia y la doctrina del libre albedrío? ¿De qué manera se compatibiliza con la libertad del hombre? Se recurrirá a axiomas del tipo «Astra inclinant non necessitant». Tycho-Brahe nos recordará que «El hombre posee una fuerza mayor que la de los astros, para contrarrestrar su influjo, si vive según justicia»" ${ }^{\prime \prime}$.

Un esquema muy manejado (y supuesto mejor) en muchos casos es el de la división ternaria del universo. Existe una triple correspondencia: 1. Mundo Intelectual o Dios con el Cerebro 2. Astros con el Corazón 3. Minerales, animales y plantas con los Sentidos y los Fluidos del Cuerpo.

Las influencias de los astros han de extenderse a todas las cosas, pero es esencial para el astrólogo la consideración de los influjos siguientes: 1 . naciones 2. actos humanos 3. cuerpo humano.

Los planetas tienen a su vez su propio influjo que se desglosa así: Mercurio-razón, Venus-amor, Marte-acción, Júpiter-éxito, Saturno-lo que contrae. Faltan, por supuesto, Urano, Neptuno y Plutón. Además, debemos añadir a éstos el Sol y la Luna, que pese a ser cuerpos astrales diferentes se consideran también como planetas. Quizás la lógica de esto la encontremos si examinamos

17 Aunque difícilmente identificable, la figura de Hermes Trimegisto se mueve en estos ambientes culturales asociada a ideas de este tipo. Su axioma paradigmático es «lo que está arriba es igual que lo que está abajo». Quizá si conocieramos algo mejor las relaciones entre los reinos helenísticos post-alejandrinos y la India, y Asia en general, podríamos iluminar mejor la cuestión.

${ }_{18}$ En efecto, algunos influjos físicos concretos de los astros más cercanos a nosotros son conocidos desde bastante tiempo atrás; son fácilmente comprobables sin metodología científica alguna.

19 Tycho-Brache, como Kepler, es un gran astrólogo que sigue fiel a la tradición en que ha aprendido su ciencia y para él astrología y astronomía forman un cuerpo inseparable. 
su distancia, corta, con respecto a la Tierra, lo que justifica su influjo, bien patente en la práctica, como ya hemos afirmado anteriormente ${ }^{20}$.

En cuanto a los signos, cuya interpretación es plenamente tradicional, responden a los doce, bien conocidos: Aries, Tauro, Géminis, Cáncer, Leo, Virgo, Libra, Escorpio, Sagitario, Capricornio, Acuario y Piscis.

Las casas representan las doce partes en que está dividido el cielo del nativo en el momento de su alumbramiento. A cada una le corresponde un signo y una interpretación sobre el destino del nacido. Veamos algunas: 1. ARIES, ángulo oriental, casa de la vida, asegura larga existencia. 2. TAURO, puerta inferior, casa de las riquezas, provee de buena fortuna. 3. GÉMINIS, casa de los hermanos, herencias y sorpresas. 4. CÁNCER, fondo del cielo, ángulo de la tierra, casa de los parientes. Asegura bienes patrimoniales, relaciones de familia, parientes, etc... ${ }^{21}$

Bases teóricas del corpus médico clásico y su aplicación medieval. En primer lugar, las cualidades humorales son las que explican los procesos de saludenfermedad. Su equilibrio o armonía, a semejanza de la naturaleza, determina el estado de la persona. Corrigiendo este desequilibrio se acaba con la enfermedad. Los pares funcionales son los siguientes: fuego-calor, frío-tierra, sequedadaire y humedad-agua ${ }^{22}$.

Además, como veremos luego, es necesario conocer la teoría astrológica, por lo que se refiere al menos a planetas, casas y signos. Asimismo, es imprescindible tener en cuenta que las influencias astrales se extienden a todos los elementos naturales, por lo que a la hora de utilizar una determinada planta, por ejemplo, debemos conocer su planeta regente. Veamos algún caso: Saturno... roble, ruda, níspero, Júpiter... laurel, canela, bálsamo, Marte... hierro, jaspe, magnesia, etc. ${ }^{2}$

La «virtud natural» es un elemento fundamental en la teoría de la salud en este momento. El estado natural es la salud y si se rompe esta relación llega el desquilibrio. Éste se concibe, como hemos reflejado ya, en términos de cualidades humorales. Sin embargo, no se desconocen la dieta, el ejercicio y la higiene como elementos favorecedores de este estado de salud natural; lo que sucede es que se integran dentro de las concepciones humorales al igual que el resto ${ }^{24}$.

20 Vid. n. 18

${ }^{21}$ Sobre esto, vid. M.V. AMASUNO en bibliografía anexa.

22 M.V. Amasuno, Eclipse del sol..., op. cit. Bibliografía, pp. 20-21. Asimismo R. TATON, $H^{a}$ general de las Ciencias, París, PUF, 1957, p. 467.

${ }^{23}$ M.V. AMASUNO, op. cit., p. 25.

24 R. TATON, op. cit., p. 469. 


\section{LA PRAXIS}

Reglas prácticas de aplicación en el campo astrológico. Las reglas de aplicación se basan, implícitamente, en una noción clave que subyace a todas ellas y que podríamos denominar "poder planetario» "s. Es imprescindible conocer los «aspectos» de los diferentes planetas para poder estudiar un horóscopo. A su vez, también en una ordenación interna no explicitada, se refleja una división en el poder planetario que tiene dos vertientes: el poder cualitativo y el poder cuantitativo. 1. El poder cualitativo consiste en la calidad de la influencia ejercida por cada planeta: el Sol-benéfica, la Luna-melancólica, Mercurioinconstante... 2. El poder cuantitativo. Es un apartado sumamente importante y cuya aplicación al natalicio de cualquier persona, o a su enfermedad determinan prácticamente toda conducta que se deba adoptar o evitar. El signo, la casa, el aspecto y algún anexo más son los elementos configurantes. Así pues, debemos tener en cuenta los siguientes puntos: a) El signo del Zodíaco en que está situado en ese momento (la persona, la enfermedad, lo que sea) b) El signo del cual el planeta es señor $c$ ) El signo en que el planeta se alegra d) El signo en que el planeta asciende o desciende e) La casa en que el planeta está situado $f$ ) La casa en que el planeta se alegra $\mathrm{g}$ ) El aspecto del planeta $\mathrm{h}$ ) $\mathrm{El}$ aspecto del planeta en el ascendente i) El movimiento del planeta j) El día y la hora ${ }^{26}$.

El método de aplicación de la medicina. Médicos bebreos, musulmanes y cristianos. Todo lo mencionado en el apartado anterior tiene su uso médico, tomando como problema astrológico tipo uno muy definido, la enfermedad concreta.

Pero además la descripción de dietas, enfermedades, antídotos y venenos varios cubría una parte muy importante del saber médico. Lapidarios, herbarios, libros de toxicología ocupan un papel importante en la formación del médico medieval, cristiano, árabe o judío.

El medio musulman tiene en el ambiente médico general una importancia excepcional. Grandes compilaciones de todos los saberes de la profesión. Los aforismos de Ibn Massawayh nos dan la clave de cualquier tratamiento médico: la individualidad del enfermo es esencial para el médico musulman ${ }^{27}$. La concepción de «natura medicatrix» es inherente a cualquier tratamiento sana-

${ }^{25}$ M.V. Amasuno, op. cit., p. 25.

${ }^{26}$ M.V. AMASUnO, op. cit., p. 25, y L.A. Mercier, Astrology in Medicine, London, 1914, p. 20.

27 Vid. nota 24. Además D. CAMPBell, Arabian Medicine and its influence on the Middle Ages, London, 1984 
dor. Así, el aforismo 61 nos dice que «Es necesario que el médico en su tratamiento se asimile a la acción de la naturaleza». El esquema terapéutico global podría ser como sigue: 1) Dieta general y dietas específicas, ejercicio, actitud psicológica del paciente, etc. 2) Medicamentos, aplicados sólo en caso de necesidad. Un buen ejemplo de esto lo tenemos en el «Libro de las drogas» de Al-Biruni.

A esto se añadirán los elementos de carácter astrológico más curiosos que podamos encontrar y, finalmente, los de carácter mágico como los amuletos, rollos de oración, exorcismos, etc. ${ }^{28}$

El diagnóstico se extrae de consideraciones generales sobre los humores. Dos notas son fundamentales: el pulso y la orina. En general, los médicos árabes se distinguirán por la buena anotación de síntomas patológicos, indicio de enfermedades variadas. Ibn-al-Nafis hablará de la pequeña circulación y nos dirá que los espíritus animales engendrados en el ventrículo izquierdo llevan la sangre a los pulmones donde se mezcla con el aire y luego se distribuye al cuerpo. Se refina o limpia en el ventrículo derecho. Todas estas nociones de aplicación de conocimientos médicos fueron bien conocidas en la España musulmana y, aún más, son hispanoárabes algunos de los más grandes maestros ${ }^{29}$.

Los hebreos, dado su papel de cultura insertada en otras más amplias y de cuyas diferentes estructuras políticas dependen, y a la vez prescinden, tienen un carácter peculiar. En un principio se crean libros de drogas y venenos, como el de Altalhisi («El resumen») de Abu'l Merwan Ibn Ganah con una relación de medicamentos en árabe, persa, sirio, griego, castellano y bereber. Desgraciadamente, esta obra la conocemos sólo por los comentarios de Maimónides y de Ibn-AlBaytar. De especial interés son además el «Libro de drogas» de Assaph ha Yehudi (siglo VIII), o el «Libro Precioso» de Donnolo (siglo X) o el precioso estudio de Maimónides sobre medicamentos en donde estudia más de 1800 drogas ${ }^{30}$.

En cuanto a los tratamientos destaca Isaac Ben Salomon Israeli. Su tratado de las «Dietas» fue uno de los más utilizados en toda la Edad Media y Renacimiento. Pero sobre todos ellos es Maimónides quien sienta las bases del hebraísmo médico. Sus trabajos: «Materia médica», «La conservación de la salud», "Las hemorroides», "La vida conyugal», "Venenos y antídotos», etc. constituyen la cima del saber médico hebreo medieval. Escritos todos en árabe se traducen enseguida al hebreo, latín, francés, castellano, alemán, inglés, etc. De forma muy simple podríamos decir que los presupuestos básicos a lo largo de su obra son: a) La higiene b) La naturaleza como agente autorreparador ${ }^{31}$.

28 Vid. n. 5.

29 Vid. n. 27.

${ }^{30}$ Ibidem, pp. 513-515.

3 Al igual que los musulmanes. Vid. n. 24. 
Los médicos cristianos heredan una fuerte tradición musulmana y hebrea. Importantes médicos y tratados de teoría médica musulmanes y hebreos constituyen la base de la enseñanza en la Península Ibérica, Francia, Italia,... Así, es lógico, pues, que médicos como Alonso de Chirino insistan en que la intervención del médico en la "curación natural del enfermo" ha de ser la menor posible.

En Sevilla en 1376-78 los libros de ciencia médica se escriben en árabe y hebreo. Desde el siglo XIII la Universidad produce títulos de bachiller, licenciado y doctor. Sin embargo, será ya desde mediados del XIV cuando su influjo sea determinante, y aún así el aprendizaje libre y el paso de exámenes por los delegados reales o municipales es muy frecuente. La enseñanza universitaria es muy teórica: «lectio», "disputatio" y "repetitio» o «exercitium». Por eso, las prácticas con médicos hebreos y/o musulmanes se hacen imprescindibles para una completa formación ${ }^{32}$.

Debido a los fallos, la legislación es dura, y si la práctica médica acarrea daños se estipulan penas muy gravosas 3 .

\section{LA CONEXIÓN MÉDICO-ASTROLÓGICA}

De lo visto hasta el momento, se desprende de forma indudable una relación profunda entre ambas disciplinas. No obstante, es mejor que lo verifiquemos de forma concreta.

En el Códice de Gerona ${ }^{34}$, texto médico de relieve, se conserva la "Astrología Ypocrates»" ", que fue muy utilizada en la Península y cuyo texto, traducido por Guillermo de Moerbeke, enlaza de forma tajante el estudio de la medicina y el cultivo de la ciencia astrológica. Así, nos dice: "Quis medicus est qui astronomiam ignorat. Nemo in manibus illius se commitere debet».

Arnaldo de Vilanova reduce los preceptos astrológicos a tener en cuenta, para la curación del enfermo, a los siguientes: 1) La cosa que concierna a la pregunta formulada 2) El signo que está en el ascendente 3) El señor de éste (¿signo o ascendente?) 4) El signo que está en la casa sobre la cual se ha

32 L. GRANIEL, op. cit., pp. 121 y 127.

${ }^{33}$ Así se aplican para los que no conocen el oficio pero lo ejercen, para los que equivocan las medicinas en un tratamiento, etc. Esto es evidente en la 7. Partida Título 8, Ley 6, y en esta misma Partida en el Título 15, Ley 9.

34 B.C. 75 ff. 113v-116. Guy BEAUJOUAN, Manuscrits médicaux conservés en Espagne, «Mélanges de la Casa de Velázquez», VIII, París, 1972, p. 187.

"Comentarios al códice y otras versiones de transmisión en P. KIBRE, Studies in Medieval Science, London, 1984. 
realizado la pregunta. En caso de una enfermedad, ésta puede ser la primera (la casa de la vida), la octava (la casa de la muerte), o la sexta, es decir, la de las enfermedades). 5) Su señor (¿del signo o de la casa?) 6) Su relación con el ascendente 7) Su relación con la Luna ". Todos estos factores se pueden interpretar de la siguiente forma: a) el ascendente y su señor significan el enfermo. b) El medio cielo (la décima casa) significa el médico. c) La sexta casa y su señor significan la enfermedad del paciente. d) La cuarta casa y su señor significan su médico. Las consecuencias son entendidas en un sistema binario: así para el punto a, si el ascendente es bueno el paciente mejora, si es malo empeora; para el punto b, si la décima casa tiene un buen aspecto el enfermo sana, si es malo empeora; para los puntos c y d, lo mismo "."

Además, son múltiples las incidencias del cielo que pueden intervenir en el proceso patológico del paciente. Si el signo del ascendente es móvil y la Luna está en signo móvil como Aries, Cáncer, Libra o Capricornio, y el señor de ascendente estuviera en iguales circunstancias, la enfermedad terminará pronto para bien o para mal. Por contra, si está en signos estables como Tauro, Leo, Escorpión o Acuario, acarrea una enfermedad larga. Si el señor del ascendente y la Luna fueran propicios y estuvieran exentos de las adversas influencias de otros planetas, la enfermedad terminaría felizmente, aún más si ambos están en aspecto favorable con la VIII casa (la muerte). La muerte es segura si: 1 . La Luna, el señor del ascendente, o el señor de la casa de la enfermedad (la VI) estuvieran a 15 o menos grados del sol y su movimiento fuera retrógrado. 2 . La Luna estuviese en conjunción con Marte o Saturno. 3. La Luna estuviese en la casa de la muerte. 4. Si la casa de la muerte y el señor de la casa de la enfermedad se ven fortalecidos. Como vemos la Luna tiene especial importancia, de ahí que en la práctica se utilizase de forma regular sin añadir cálculos complementarios ${ }^{38}$.

Eso queda patente en el Tratado del Pseudo-Hipócrates titulado «Tractatus ad medicos dirigendum», que es una guía para médicos, traducido por Guillermo de Moerbeke, consagrado para el diagnóstico de las enfermedades en función de la Luna ".

Además, el tratamiento ha de tener en cuenta las facultades naturales: retentiva, digestiva, expulsiva, atractiva, vegetativa y generatriz. Según la medicina que se administre en cada momento astral determinado, la función variará con resultados contrapuestos, benéficos o mortales.

${ }^{36}$ M.V. Amasuno, op. cit., p. 37. n. 47.

17. Ibidem

${ }_{38}$ También Galeno opina que los días críticos se corresponden con las fases de la Luna. Esto dejará una huella imborrable en todo el «galenismo medieval», tanto cristiano como hebreo o musulmán.

39 M. PRÉAUD. Les astrologues à..., p. 242. 
Los días críticos suponen una coordenada temporal en la cual la enfermedad se cura, en la que se muere o se pasa a una molesta cronicidad en su padecimiento. La crisis de ésta ha de ser: 1) Completa 2) No debe presentar más afecciones 3) Manifiesta, esto es, con materia visible 4) Indicativa, o sea clara y definida, sin posibilidad de error ${ }^{40}$.

La terapéutica tendrá pues como base, al igual que la astrología, la analogía. Así pues, si una enfermedad se produce por humedad es debido a la Luna, y el tratamiento a aplicar se basará en medicamentos solares, que aporten al enfermo la sequedad requerida para restablecer el equilibrio. De la misma manera, cada planta tiene un momento de recogida, secado y aplicación al paciente en función de estas analogías. Además, anatómicamente, existe una relación tajante, muchas veces representada. Así, Aries-Cabeza, Tauro-Cuello, Géminis-Brazos y espaldas,..."

Finalmente, recordemos que las escuelas de medicina de París eran conocidas como «Facultas Saluberrima Medicinae et Astrologiae»; y como en ésta, en 1437 , el rector nombra una comisión de sabios para dictaminar sobre los influjos producidos por las conjunciones y las oposiciones del Sol y de la Luna o, también, pensemos en los famosos debates que se establecieron sobre la conveniencia de elegir determinados días para las purgas y sangrías entre Roland l'Écrivain y Laurent Muste ${ }^{42}$.

\section{HOY EL HISTORIADOR. PROVECHO MATERIAL}

Son variadas las razones que aconsejan un estudio conjunto y detenido de ambas disciplinas, integradas en un corpus de conocimiento unitario. Entre otras citemos las siguientes: 1) Constituyen un importante testimonio para la Historia de las ciencias en la Edad Media. 2) Proporcionan datos de valor incalculable para la tan recurrida «Historia de las mentalidades». Nos proporciona, en efecto, grados de creencia y aceptación de diversas prácticas «científicas» a lo largo de nuestro período de estudio. Es posible, a mi juicio, adaptar un término como el de "Grand Peur», con el arrastre de supuestos conceptuales que conlleva y aplicarlo a momentos diferentes de múltiples conflictos medievales (Guerra de los 100 Años en Europa y el anexo Trastamara en España, por ejemplo). En estos casos, el estudio de las predicciones extraídas de eclipses o de

40 M.V. Amasuno, op. cit., pp. 434-47.

${ }^{41}$ Más curioso es, sin embargo, el caballo astrológico del British Museum, Add. 15097, fol. 59, Londres.

${ }_{42}$ M. PrÉAUd, op. cit., p. 185. 
conjunciones planetarias "catastróficas" nos permite acceder a la difusión de las mismas en ambientes populares y la influencia de éstas en medios sociales tan agitados. 3) Nos proporciona útiles de trabajo inapreciables para el quehacer histórico como son el fechado astrológico, aplicable a personas y a sucesos, o el conocimiento de las natividades de famosos personajes. 4) $\mathrm{La}$ propaganda política que se mueve en torno a las predicciones astrológicas es fulminante. Los cambios, o intentos de manejo, de la opinión pública a través de la difusión de predicciones son un hecho inapelable ${ }^{43}$. 5) El peso en las decisiones de los monarcas, nobles y obispos, a los que su médico (el que vela por su salud y, en último extremo, por su vida) y su astrólogo (el mismo médicol es tan grande que los determina profundamente en un sentido o en otro. Sírvanos de ejemplo Carlos V quien dotó a Du Guesclin de un astrólogo para que le guiara en sus operaciones militares ${ }^{44}$.

\section{MÉdICOS Y ASTRÓLOGOS PENINSULARES}

Como sabemos la mayoría de los profesionales en una de estas dos ramas lo son en mayor o menor grado en la otra. Los médicos-astrólogos judíos ocupan buena parte de los cargos cortesanos en estas especialidades. Así, serán judíos los médicos de Alfonso VI, Alfonso X, Alfonso XI, Enrique III, etc. ${ }^{45}$ Recordemos también que el médico de Juan II de Portugal, José Vecinho, era hebreo. Hubo, sin embargo, numerosas prohibiciones de ejercer la medicina para los hebreos tanto en campo cristiano como musulmán y, a su vez, entre estos mismos. En la práctica, tan diferente de la realidad como de costumbre, el ejercicio de la medicina por miembros distintos a los de la comunidad políticamente gobernante era un hecho generalizado ${ }^{46}$.

Ya en el siglo X, entre los cristianos, encontramos a "Oliva», monje y abad de Ripoll, conocedor de textos astronómicos-astrológicos, y a un tal «Lupitus» de Barcelona, que tradujo del árabe al latín un libro de astrología, que no conservamos ${ }^{47}$.

43. Así las de Conrad Heingarter en 1476, a favor de Luis XI y contra el Duque de Borgoña, Carlos el Temerario, M. PRÉAUD, op. cit., p. 155.

${ }^{44}$ Luis VII, tras consultar a un astrónomo, Guillermo el Español, sobre el eclipse de 11 de julio de 1154, desposa aquel mismo año a Constanza de Castilla.

is R. TATON, op. cit., p. 512.

${ }^{46}$ Las prohibiciones de la "hisba» son terminantes en este punto. Igual sucede si revisamos la legislación cristiana (Partidas, Fueros y Cartas puebla, Ordenamientos, etc.).

47 Sería de enorme interés si tuviéramos la suerte de encontrarlo o, al menos, de poseer más referencias indirectas sobre el mismo. 
En el siglo XI el barcelonés Abraham ben Chija destaca como médico, tratadista y astrólogo ${ }^{48}$. En el XII es figura señera la de Abraham Meir Ben Ezra, también de Barcelona, quien compuso un libro astrológico en hebreo, que se tradujo al catalán con el título de "Lo llibre dels juheus de les estrelles" ". En el XIII son notorios los trabajos de compilación en torno a la figura de Alfonso X el Sabio en la Corona de Castilla. Entretanto, en Aragón, la gran personalidad de Arnaldo de Vilanova destaca en todos los terrenos, como profesor tratadista, médico, etc. siendo el más importante representante del galenismo islámico en la cristiandad ". En el XIV con Pedro el Ceremonioso se protege a Dalmau Planes quien compone el «Tractat d'astrología o sciencia de les steles...». En Castilla con Alfonso XI, Ibn Wakar escribe su «Regia medicina practica Castellae» de excepcional importancia como hito en la medicina castellana. En el siglo XV son bastantes los nombres a destacar: Fr. Anselmo Turmeda, Bernardo de Granollachs, mosén Juan Pedro... Sin embargo, recalemos en la figura del astromédico Crexhas Abiatar, formado en la cirugía de Abulcasis y en la oftalmología de Alcoatí, que realizó también con éxito la operación de una catarata a Juan II de Aragón "1. Citemos, asimismo, el «Libro de astrología» y el "Arte cisoria» de Enrique de Villena, de gran difusión merced a la especial relevancia de su autor ${ }^{52}$. Finalmente, recordemos que en 1386 la astrología figura como materia de examen en una autorización para ejercer la medicina a favor del judío Bendit Caracosa ${ }^{53}$. No obstante, lejos de existir una versión uniforme de estas disciplinas hacia el lado positivo de su apreciación existe un saludable recelo natural con respecto a éstas, como expresa Alonso Chirino, ya que muchas personas «faziendose fisicos, pasan por astrologos, o faziendose astrologos pasan por fisicos, cuando ambas disciplinas... son de muchas dudas e non de menos mentir la una que la otran ${ }^{54}$.

48 Son obras suyas el Sphera mundi y el Tractat dels planetes.

19 Concurrió a la cita de astrólogos de 1186 en la que se anunciaba un tremendo suceso debido a una conjunción de planetas.

so Destaquemos, entre sus numerosas obras, las siguientes: De Judicii die, Sigilla duodecim pro totidem caelestibus signis, Capitula astrologiae de judiciis infirmitatum secundum motum de planetarum, Aphorismi de ingenio sanitatis, Speculum medicinae, y el Antidotarium.

"Abulcasis redactó el "Al-Tasrif» dedicado a la cirugía, libro de enorme difusión. Otras figuras de relieve serán Avenzoar que compuso el "Al-Taysir» o Averroes, con su Famoso "Colliget» o el «De venenis». Luego, la lista se haría interminable: Ibn-al-Wafid, Avenpace, Ibn Tufail, etc.

32 Sin embargo, no es más que una buena versión de los clásicos musulmanes y hebreos que no aporta demasiado, a no ser su vulgarización en el mundo médico cristiano, donde, por otra parte, no eran desconocidos, sino muy manejados en versiones diferentes en sus idiomas originales e incluso en otros romances.

5.3 L. GRANIEL, op. cit., p. 160.

\$4 Ibidem. 


\section{MANUSCRITOS Y CÓDICES}

Muy brevemente debemos hacer alusión a la cantidad tan alta de códices y manuscritos referentes a estos temas que duermen en el polvo de nuestros archivos esperando la mirada del estudioso; citemos algunos: 1) la "Astronomía» de Cicerón en un texto latino del XII" 2) el "Liber Astronomicus» de Alfagrani en un texto del XIV "3) un "Liber Medicinae» del XV, sin atribución alguna "4) los «De venenis" y "De generatione sanguinis» de Averroes, en un manuscrito del XVI ${ }^{88} 5$ ) el "Tratado de astronomía» de Alí ibn Hacein, en un texto manuscrito del XV" 6 ) otro "Tratado de astrología», anónimo, del siglo $\mathrm{XV}$, perteneciente al área catalana ${ }^{60} 7$ ) el "Juicio de las estrellas» de Alyh Aben Ragel, en un texto manuscrito del siglo XIII ${ }^{61} 8$ ) el «Inventarii o collectarii de cirugia» de Guido de Cauliaco, impreso en Barcelona en 1492...

\section{JOSÉ MANUEL GONZÁLEZ SÁNCHEZ Arcbivo Histórico Nacional (Madrid)}

"Efectivamente se dedicó Cicerón a la astrología griega en sus años mozos. Luego la condenaría en De divinatione. Es un texto clásico, antes de que se consume la plena recepción del corpus judío y árabe del XII-XIII.

${ }^{56}$ Es el Liber astronomicus, de Alfagrani, en traducción de Juan de Sevilla. M.V. AMASUNO, op. cit., habla de Juan de Sevilla como traductor del famoso Abulmasar; no es extraño, pues, que también lo fuera de Alfagrani. Conrad Heingarter lo utiliza para extraer una especie de compilación sobre las latitudes de los planetas, M. PRÉAUD, op. cit., p. 242.

"Se encuentra en la Catedral de Segovia y tiene una extención considerable. No cabe duda alguna de su interés, no siendo además, seguramente, muy difícil adscribirle a una escuela determinada.

is El De venenis... se inscribe en la amplia producción de libros de drogas y toxicología; no es de los mejores, pero la importancia de su autor le hizo merecer especial renombre.

59 Se encuentra también en la Catedral de Segovia. Sus condiciones son similares a las del manuscrito de la n. 57, aunque éste es un poco más breve.

${ }^{61}$ Es un tratado de carácter "breve», pero que registra gran cantidad de datos de intrés. Está en el Archivo episcopal de Vich.

61 M.V. AMASUNO op. cit., p. 12, nos dice que fue traducido al castellano en 1256 por Judah Ben Moses. M. PRÉAUD, op. cit. p. 242, anota que su primera traducción latina fue realizada por Egidio de Tebaldis. ęs ésta la de Ben Moses, o quizá otra diferente o incluso anterior?

${ }^{62}$ M.V. AMASUNO, op. cit., p. 103, afirma que su $1 .^{a}$ edición latina es la realizada en Venecia en 1498. Debemos rectificar el parecer de tan notable estudioso y dar por más correcta la fecha de 1492 en Barcelona como la más antigua conocida hasta el momento presente, que es la de esta obra impresa, conservada hoy en la Biblioteca Universitaria de Barcelona. 


\section{RÉSUMÉ}

La médecine et l'astrologie, unies dans un recueil de connaissance commune, qui embrasse une cosmovision de la vie en tant que relation intégrale entre l'homme, la nature et l'univers, est un des thèmes les plus interessants des sciences médiévalos. Dans ce travail, on ébauche les sujets suivants: comment et quelle est la théorie qui les nourrit? Comment et quelle en est la pratique quotidienne? Quelle son leurs relations? Quels renseignements nous fournissent ces sources pour mieux connaître les sociétés dans lesquelles elles se déroulent? etc.

On cite en même temps les médecins et les astrologues les plus connus de la péninsule et on repasse brièvement quelques-uns de leurs écrits les plus intéressants.

\section{SUMMARY}

Medicine and astrology, united in a common corpus of knowledge, that includes a cosmovision of life as an integral relation between mankind, nature and universe, is one of the best chapters of medieval sciences. We sketch in this work: a) How it supports itself and which are the theories that allow to do so; b) What is its daily practice; c) How they are interconnected; d) What kind of information these sources supply us with to know better the societies in which they develop themselves; etc.

In the same way, we give some examples of the physicians and astrologists of the peninsula that are the best known and we pass in review some of the most interesting documents. 